\title{
Surface Treatment by Different Parameters of Erbium:Yttrium-Aluminum-Garnet (Er:YAG) Laser: Scanning Electron Microscope (SEM) Evaluation
}

\author{
Nasim Chiniforush', Hanieh Nokhbatolfoghahaei ${ }^{*}$, Abbas Monzavi ${ }^{2}$, Edris Pordel ${ }^{1}$, Sajjad Ashnagar $^{3}$ \\ ${ }^{1}$ Laser Research Center of Dentistry (LRCD), Dental Research Institute, Tehran University of Medical Sciences, \\ Tehran, Iran \\ ${ }^{2}$ Department of Dental Prosthesis and Implants, Laser Research Center of Dentistry, School of Dentistry, Tehran \\ University of Medical Sciences, Tehran, Iran \\ ${ }^{3}$ Department of Periodontics and Oral Medicine, Michigan School of Dentistry, MI, USA
}

\author{
*Correspondence to \\ Hanieh Nokhbatolfoghahaei, \\ DDS; Laser Research Center of \\ Dentistry, School of Dentistry, \\ Tehran University of Medical \\ Sciences, Tehran, Iran. \\ Tel: +98-2188015017; \\ Fax: +98-2188687471 \\ Email: \\ h-nokhbeh@farabi.tums.ac.ir
}

Published online 7 January 2016

\begin{abstract}
Introduction: This study aimed to assess the Scanning Electron Microscope (SEM) analysis of tooth surface irradiated by erbium:yttrium-aluminum-garnet (Er:YAG) laser with various parameters.

Methods: Number of 25 extracted human third molars free of caries were used in this study. The teeth were put into 5 groups for laser irradiation as follows: group 1 (power: $0.5 \mathrm{~W}$, Energy: $50 \mathrm{~mJ}$ ); group 2 (power: $1 \mathrm{~W}$, Energy: $100 \mathrm{~mJ}$ ); group 3 (power: $1.5 \mathrm{~W}$, Energy: $150 \mathrm{~mJ}$ ); group 4 (power: $2 \mathrm{~W}$, Energy: $200 \mathrm{~mJ}$ ); group 5 (power: $2.5 \mathrm{~W}$, Energy: $250 \mathrm{~mJ}$ ). All samples were prepared by repetition rate of $10 \mathrm{~Hz}$ and duration of $230 \mu \mathrm{s}$, using a non-contact handpiece at a distance of $4 \mathrm{~mm}$. Then, the samples were prepared for SEM examination.

Results: SEM evaluation of every 25 samples, treated by Er:YAG, showed that all groups had exposed dentinal tubules without any melted area or cracks.

Conclusion: In this study we used SEM to investigate ablated dentine with different parameters of Er:YAG laser energy. Our findings support these conclusions. All powers of laser below 3 $\mathrm{W}$ are proper for ablation, and make no cracks.

Keywords: Dentinal tubules; Laser; Scanning electron microscopy; Er:YAG.
\end{abstract}

\section{Introduction}

The first laser was invented by Maimann in1967, and several years later, it was used in dentistry. Carbon dioxide $\left(\mathrm{CO}_{2}\right)$ laser and neodymium-doped yttrium aluminium garnet (Nd:YAG) lasers were used in the past for soft tissue surgery and also cavity preparation, but had thermal effects on pulp and surrounding tissues. ${ }^{1,2}$ So erbium family were introduced including Er:YAG (2940 nm) and Er, Cr:YSGG $(2780 \mathrm{~nm})$. These wavelengths are absorbed by water and hydroxyapatite, so they are suitable for removing dental hard tissues, and produce no cracks or melting area. $^{3}$

Advantages of using Er:YAG laser instead of dental drill include making no noise or vibration, and producing open dentinal tubules on dental surface without any smear layer. However, some studies showed that morphological changes of enamel surface lased with Er:YAG do not create effective bond between composite and dental surface. ${ }^{4,5}$ Another property in cavity preparation with laser is that there are no boxes but irregular cavities.

Irregularity is the main characteristic of cavity prepared by laser, because laser only removes caries and follows their pattern of progress. So composite restorations are preferred to amalgam restorations. ${ }^{5}$

The aim of this study was to survey the dental surfaces prepared with different parameters of Er:YAG laser to define an optimal laser energy suitable for composite bonding to dental surface.

\section{Methods}

Twenty-five human third molars which were free from any kind of caries or restorations were extracted and used in this study. The teeth were cleaned with water and stored in $0.4 \%$ thymol solution for about 30 days, in order to prevent microbial growth; the enamel was removed by diamond bur. Then, they were divided into five groups, including (a) group 1: Power: $0.5 \mathrm{~W}$, Energy: $50 \mathrm{mj},(b)$ group 2: Power: $1 \mathrm{~W}$, Energy: $100 \mathrm{mj}$, (c) group 3: Power: $1.5 \mathrm{~W}$, Energy: $150 \mathrm{mj},(d)$ group 4: Power: $2 \mathrm{~W}$, Energy: $200 \mathrm{mj}$, (e) group 5: Power: $2.5 \mathrm{~W}$, Energy: $250 \mathrm{mj}$.

In the present study, the irradiation was performed with Er:YAG laser (Deka, Italy), with wavelength of $2940 \mathrm{~nm}$,

Please cite this article as follows: Chiniforush N, Nokhbatolfoghahaei H, Monzavi A, Pordel E, Ashnagar S. Surface treatment by different parameters of erbium:yttrium-aluminum-garnet (Er:YAG) laser: scanning electron microscope (SEM) evaluation. I Lasers Med Sci. 2016;7(1):37-39. doi:10.15171/jlms.2016.08. 
repetition rate of $10 \mathrm{~Hz}$ and pulse duration of $230 \mu$ s (considered very short pulse); and the non-contact handpiece of laser was placed about $4 \mathrm{~mm}$ above the surface.

Preparation of samples for scanning electron microscope (SEM) analysis was done by immersing them in $2.5 \%$ glutaraldehyde solution for 12 hours at temperature of $4^{\circ} \mathrm{C}$ to be fixed. Rinsing with distilled water was done in next. Samples were subjected to dehydration using ascending grades of ethanol as follow; 25\% for 20 minutes with 25\%, 20 minutes with 50\%, 20 minutes with $75 \%, 30$ minutes with $95 \%$ and 1 hour with $100 \%$ solution). Finally drying of the samples with absorbing paper was carried out. Before subjecting samples to SEM analysis, they were sputter coated with gold as processing before SEM observation. Analysis was done using SEM in three magnifications: $\mathrm{x} 500, \mathrm{x} 1000$ and $\mathrm{x} 5000$.

\section{Results}

SEM evaluation of every 25 samples treated by Er:YAG laser showed that all groups had exposed dentinal tubules without any melting area or cracks (Figure 1).

Pictures with x5000 magnification showed recrystallization around dentinal tubules (Figures 1, 2, 3).

In this study all the 5 ranges of power for Er:YAG were suitable and produced dentinal tubules with no melting area and smear layer.

By increasing the power, open dentinal tubules became more obvious and more irregularities could be observed, manifested by a rough surface.

\section{Discussion}

The application of laser in restorative dentistry has risen up to overcome the limitations of conventional methods. Cavity preparation is one of the areas of focus on which researchers are trying to find a suitable replacement for

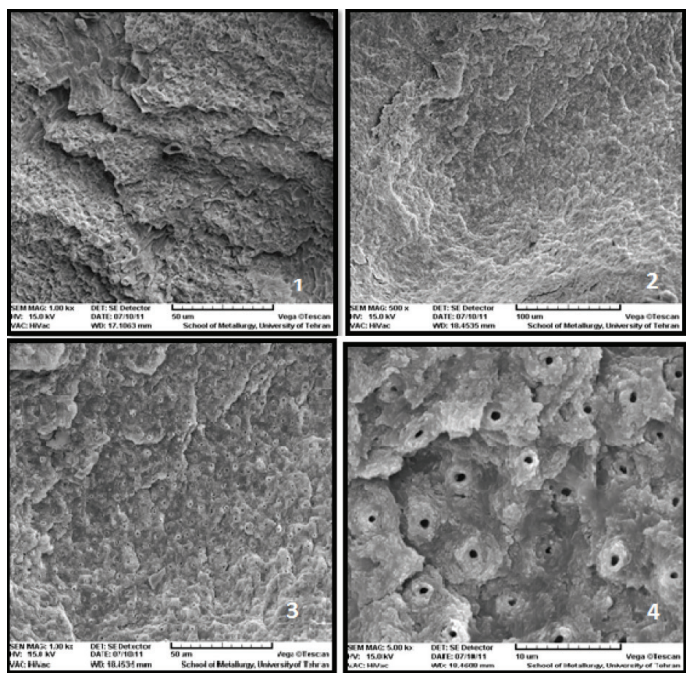

Figure 1. 1) Surface treated by Er:YAG with power $0.5 \mathrm{~W}$. (Original magnification $\times 500$, bar $=50 \mu \mathrm{m}$ ). 2) surface treated by Er:YAG with power $1 \mathrm{~W}$. (Original magnification $\times 500$, bar $=100$ $\mu \mathrm{m}) .3$ ) surface treated by Er:YAG with power $1 \mathrm{~W}$. (Original magnification $\times 1000$, bar $=50 \mu \mathrm{m})$. 4) surface treated by Er:YAG with power $1 \mathrm{~W}$.(Original magnification $\times 5000$, bar $=10 \mu \mathrm{m}$. conventional bur drilling. Dental composite, as a popular restorative material, gets bond to tooth by means of micromechanical retention of resin based materials into dentinal tubules spaces. Opening of these spaces directly affects the bond strength between composite and tooth surface. ${ }^{6,7}$

In the present study, we evaluated the surface of ablated dentin with different powers of Er:YAG laser. As shown in SEM images, all experimental groups had opened dentinal tubules without formation of smear layer. This structure allows the development of resin tags, resulting in higher bond strength between the composite and the

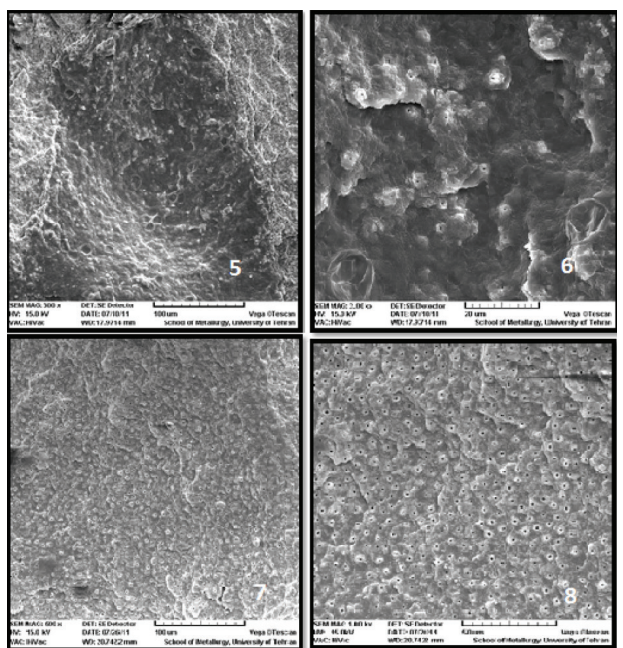

Figure 2. 5) Surface treated by Er:YAG with power $1.5 \mathrm{~W}$. (Original magnification $\times 500$, bar $=100 \mu \mathrm{m}$ ). 6) surface treated by Er:YAG with power 1.5 W.(Original magnification $\times 2000$, bar $=20 \mu \mathrm{m}$ ). 7) surface treated by Er:YAG with power $2 \mathrm{~W}$. (Original magnification $\times 500$, bar $=100 \mu \mathrm{m})$. 8) surface treated by Er:YAG with power $2 \mathrm{~W}$. (Original magnification $\times 1000$, bar $=50 \mu \mathrm{m}$ )

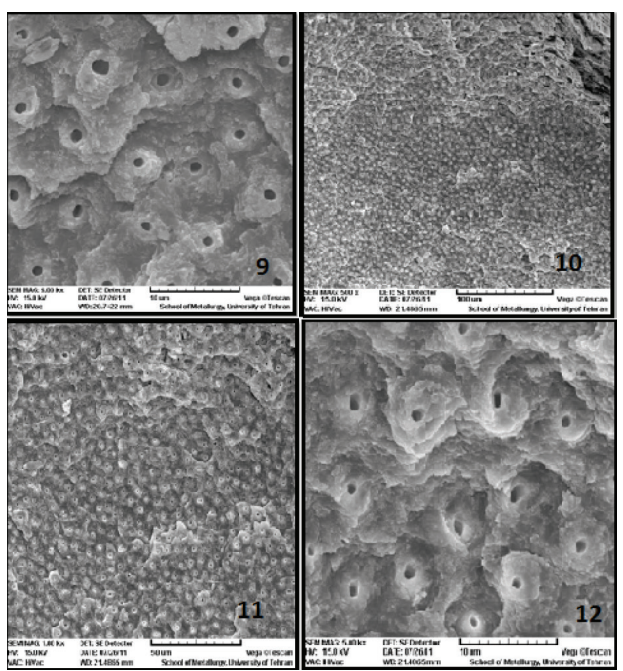

Figure 3. 9) Surface treated by Er:YAG with power 2 W. (Original magnification $\times 5000$, bar $=10 \mu \mathrm{m}) .10$ ) surface treated by Er:YAG with power $2.5 \mathrm{~W}$. (Original magnification $\times 500$, bar $=100$ $\mu \mathrm{m})$. 11) surface treated by Er:YAG with power $2.5 \mathrm{~W}$. (Original magnification $\times 1000$, bar $=50 \mu \mathrm{m})$. 12) surface treated by Er:YAG with power $2.5 \mathrm{~W}$. (Original magnification x5000, bar=10 $\mu \mathrm{m}$ ). 
dentinal surface.

These findings are in accordance with the results of Freitas et $\mathrm{al}^{8}{ }^{8}$ which concluded that different repetition rates and energies of Er:YAG laser lead to desirable irregular surfaces, free of smear layer, with opened entrance of dentinal tubules, suitable for formation of resin tags.

Another study ${ }^{9}$ showed that utilizing higher energy of Er:YAG laser, more than $3 \mathrm{~W}$, leads to dentin melting. This issue is in agreement with this study, though this study confirmed that powers below $3 \mathrm{~W}$ do not have any adverse effect.

However, in the study of Ekworapoj et $\mathrm{al}^{10}$ regarding the effect of different parameters of erbium, chromium doped yttrium scandium gallium garnet (Er-Cr: YSGG) laser, even in ablation with power 3 and $4 \mathrm{~W}$, there were open dentinal tubules without creation of smear layer and melting. Of course water-mediated ablation in both Er:YAG and Er, Cr:YSGG should be used to avoid melting and carbonization.

Another study has investigated the influence of different output powers of Er:YAG, concluded that the output power is important in ablation efficiency and creates different shapes such as box, polygonal and bowel shaped architecture. $^{11}$

SEM images of experimental groups showed recrystallization areas around dentinal tubules. These areas form after that the laser irradiated peritubular dentin begins to cool down. It is thought that due to higher collagen matrix content of intertubular dentin, laser energy absorption and ablation rate is higher in the intertubular area, in comparison with the peritubular area. ${ }^{3}$

It has to be noted that the application of Er:YAG laser for cavity preparation seems to be safe for pulpal tissue, as it just rises the temperature up to $3^{\circ} \mathrm{C}$, which is lower than $5.5^{\circ} \mathrm{C}$ change which is the threshold tolerated by a tooth. ${ }^{12}$ Other studies confirmed that the application of Er:YAG laser seems to be safe and induce a similar pulpal response, when compared with conventional bur drilling. ${ }^{13,14}$ Er:YAG laser is more comfortable and pleasant for the patient, compared to conventional drill. Also it reduces tooth hypersensivity and microbial load within the cavity. ${ }^{15}$ These facts are adjunct to suitable dentin surface treatment by Er:YAG laser, making Er:YAG laser a desirable alternative method for cavity preparation.

\section{Conclusion}

In this study we used SEM, to investigate ablated dentin with different parameters of Er:YAG laser energy. Our findings support these conclusions. All powers of laser below $3 \mathrm{~W}$ are proper for ablation, and make no cracks.

\section{Conflict of Interest}

The author has no conflict of interest to declare.

\section{References}

1. Schein MT, Bocangel JS, Nogueira GE, Schein PA. SEM evaluation of the interaction pattern between dentin and resin after cavity preparation using Er: YAG laser. J Dent. 2003;31(2):127-135. doi:10.1016/s0300-5712(03)00003-4.

2. Samad-Zadeh A, Harsono M, Belikov A, et al. The influence of laser-textured dentinal surface on bond strength. Dent Maters. 2011;27(10):1038-1044. doi:10.1016/j. dental.2011.07.005.

3. Shahabi S, Chiniforush N, Bahramian H, Monzavi A, Baghalian A, Kharazifard MJ. The effect of erbium family laser on tensile bond strength of composite to dentin in comparison with conventional method. Lasers Med Sci. 2013;28(1):139-142. doi:10.1007/s10103-012-1086-3.

4. Amaral FL, Colucci V, Souza-Gabriel AE, Chinelatti MA, Palma-Dibb RG, Corona SA. Bond durability in erbium: yttrium-aluminum-garnet laser-irradiated enamel. Lasers Med Sci. 2010;25(2):155-163.

5. Shirani F, Birang R, Malekipur MR, et al. Adhesion to Er: YAG laser and bur prepared root and crown dentine. Aust Dental J. 2012;57(2):138-143. doi:10.1111/j.18347819.2012.01682.x.

6. Arami S, Shahabi S, Tabatabaie M, Chiniforush N, Morshedi E, Torabi S. Assessing microleakage of composite restorations in class $\mathrm{V}$ cavities prepared by Er:YAG laser irradiation or diamond bur. J Conserv Dent. 2014;17(3): 216-219. doi:10.4103/0972-0707.131778.

7. Pahlavan A, Mehmanchi M, Ranjbar Omrani L, Chiniforush N. Effect of air abrasion and erbium-doped yttrium aluminum garnet (Er: YAG) laser preparation on shear bond strength of composite to dentin. J Lasers Med Sci. 2013;4(3):127-130.

8. Freitas PM, Navarro RS, Barros JA, de Paula Eduardo C. The use of Er: YAG laser for cavity preparation: an SEM evaluation. Microsc Res Tech. 2007;70(9): 803-808. doi:10.1002/jemt.20470.

9. Nokhbatolfoghahaie H, Chiniforush N, Shahabi S, Monzavi A. Scanning electron microscope (SEM) Evaluation of tooth surface irradiated by different parameters of erbium: yttrium aluminium garnet (Er: YAG) laser. J Lasers Med Sci. 2012;3(2):51-55.

10. Ekworapoj P, Sidhu SK, McCabe JF. Effect of different power parameters of Er, Cr: YSGG laser on human dentine. Lasers Med Sci. 2007;22(3):175-182. doi:10.1007/s10103006-0426-6.

11. Igarashi A, Kato J, Takase Y, Hirai Y. Influence of output energy and pulse repetition rate of the Er: YAG laser on dentin ablation. Photomed Laser Surg. 2008;26(3):189-195.

12. Zach L, Cohen G. Pulp response to externally applied heat. Oral Surg Oral Med Oral Pathol. 1965;19(4):515-530. doi:10.1016/0030-4220(65)90015-0.

13. Sonntag, KD, Klitzman B, Burkes EJ, Hoke J, Moshonov J. Pulpal response to cavity preparation with the Er: YAG and Mark III free electron lasers. Oral Surg Oral Med Oral Pathol Oral Radiol Endod. 1996;81(6): 695-702. doi:10.1016/s1079-2104(96)80076-x.

14. Rizoiu I, Kohanghadosh F, Kimmel AI, Eversole LR. Pulpal thermal responses to an erbium, chromium: YSGG pulsed laser hydrokinetic system. Oral Surg Oral Med Oral Pathol Oral Radiol Endod. 1998;86(2):220-223. doi:10.1016/ s1079-2104(98)90128-7.

15. Carrieri TC, de Freitas PM, Navarro RS, Eduardo Cde P, Mori M. Adhesion of composite luting cement to Er: YAGlaser-treated dentin. Lasers Med Sci. 2007;22(3):165-170. doi:10.1007/s10103-006-0433-7. 